\title{
TEHNOLOŠKA PRIPREMA PROIZVODNJE ALATA ZA INJEKCIONO PRESOVANJE DRŽAČA CEVI ZA PODNO GREJANJE
}

\section{TECHNOLOGICAL PREPARATION FOR THE PRODUCTION OF MOLDS FOR INJECTION OF THE UNDERFLOOR HEATING PIPE HOLDER}

\author{
Stevan Kiš, Dejan Lukić, Fakultet tehničkih nauka, Novi Sad
}

\begin{abstract}
Oblast - MAŠINSTVO
Kratak sadržaj - Osnovni predmet i cilj ovog rada se odnosi na prikaz uloge tehnološke pripreme proizvodnje u procesu izrade alata za injekciono presovanje plastike. Opisane su i realizovane aktivnosti konstruisanja alata za konkretan proizvod - držač cevi za podno grejanje, projektovanja tehnološkog procesa izrade vitalnih delova alata (kokila) kao i generisanje upravljačkih programa za njihovu obradu na CNC mašinama uz primenu programskog sistema PTC/Creo Parametric.
\end{abstract}

Ključne reči: Tehnološka priprema proizvodnje, Projektovanje alata za injekciono presovanje, Tehnološki proces izrade, CNC obrada.

Abstract - The main subject and goal of this paper is to present the role of technological preparation of production in the manufacturing process of injection molds. The activities of constructing mold for a specific product - pipe holder for underfloor heating, designing the technological process of manufacturing vital parts of mold, as well as generating numerical control program for their machining on CNC machines using the software system PTC/Creo Parametric are described and realized.

Keywords: Technological preparation of production, Injection mold design, Manufacturing process planning, CNC machining.

\section{UVOD}

Injekciono presovanje ili brizganje uz ekstrudiranje i duvanje predstavlja najrasprostranjeniju metodu proizvodnje proizvoda od plastike [1]. I pored visokih troškova osnovne opreme za injekciono presovanje plastike, koji se odnose na mašinu za brizganje, odgovarajućih alata i uređaja za temperiranje alata, ovaj postupak daje dobre tehnoekonomske efekte i kod serija od nekoliko hiljada proizvoda.

Postupak spada $\mathrm{u}$ primarnu preradu polimera $\mathrm{tj}$. preoblikovanje polimera, jer se oblik otpreska dobija od polaznog materijala koji nema određenu formu (granule, komadići i sl.).

Injekcionim presovanjem se oblikuju svi polimeri: duromeri, elastomeri, elastoplastomeri, a posebno je raširena prerada plastomernih materijala [2].

\section{NAPOMENA:}

Ovaj rad proistekao je iz master rada čiji mentor je bio dr Dejan Lukić, vanr. prof.
U fazi tehnološkog i proizvodnog osvajanja proizvoda najznačajnije mesto ima tehnološka priprema proizvodnje, koja uz konstrukcionu pripremu, ima najveći uticaj na troškove i kvalitet razvoja proizvoda, odnosno proizvodnje. Veoma je bitno da se, pored projektovanja tehnoloških procesa, izvrši analiza tehnologičnosti konstrukcionih rešenja. Da bi se to postiglo mora postojati određeni nivo simultanog odvijanja faza razvoja proizvoda, što za rezultat ima skraćenje ciklusa razvoja, smanjenje troškova i ostvarenje zadovoljavajućeg kvaliteta razvijenog proizvoda [3].

Osnovni cilj ovog rada se odnosi na prikaz uloge tehnološke pripreme proizvodnje u procesu izrade alata za injekciono presovanje polimera, kroz konstruisanje alata za konkretan proizvod-držač cevi za podno grejanje i projektovanje tehnološkog procesa izrade njegovih vitalnih delova.

\section{INJEKCIONO PRESOVANJE POLIMERA}

Polimeri se izrađuju u obliku praha, ljuspica, granula, zrnaca ili smole, a njihova prerada u gotove proizvode izvodi se procesima obrade kao što su: presovanje, istiskivanje (ekstruzija), ubrizgavanje, kalandrovanje, itd. Injekciono presovanje je proces kod koga materijal koji je potreban za proizvodnju dela ulazi u zagrevan cilindar, zamešan i proguran u kalupnu šupljinu gde se ohladi i dobija oblik kalupa. Brizganje se široko koristi za proizvodnju različitih delova, od najmanjih komponenta do čitavog tela automobila. Glavne prednosti prerade polimernih materijala ovim postupkom su $[1,2,4]$ :

- ušteda materijala,

- kraće vreme izrade gotovog proizvoda,

- velika tačnost delova, dimenzija i oblika,

- dobijaju se sjajne i glatke površine u bojama,

Proces injekcionog oblikovanja odvija se u nekoliko faza od kojih tri osnovne (slika 1):

1. Aksijalnim pomeranjem puža rastopljeni materijal se preko ulivnih kanala ubrizgava u šupljinu kalupa.

2. Obradak se hladi uz intenzivnu cirkulaciju rashladnog sredstva kroz sistem za hlađenje alata. Pri tome, puž deluje na rastopljeni materijal naknadnim pritiskom, kako bi se nadoknadio nedostatak materijala usled skupljanja otpreska pri hlađenju. Nakon završenog hlađenja otpreska, tj. na kraju faze delovanja naknadnog pritiska, puž se vraća, rotira i uvlači novu količinu granulata, topi ga i plastificira. 
3. Poslednja faza jeste otvaranje kalupa i izbacivanje obratka.
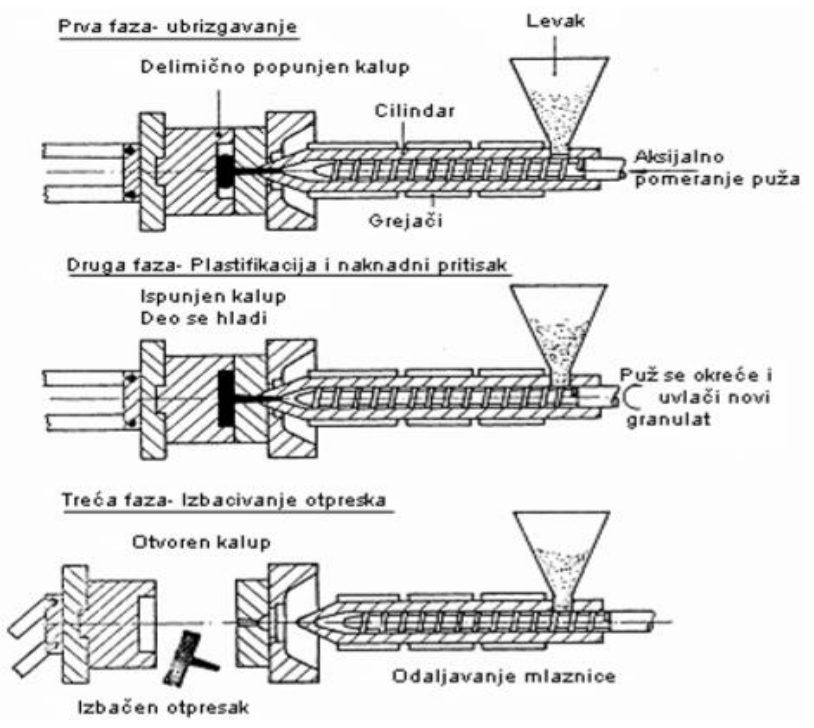

Slika 1. Faze injekcionog presovanja [2]

\section{ALATI ZA INJEKCIONO PRESOVANJE PLASTIKE}

U procesu proizvodnje proizvoda od plastike tehnologijom injekcionog presovanja-brizganja, centralni deo sistema predstavlja alat, odnosno kalup, kome su podređeni svi ostali delovi posmatranog sistema.

Alat predstavlja proizvod povišenog stepena tačnosti, zbog čega se njegovom projektovanju i izradi posvećuje posebna pažnja.

Kod oblikovanja plastomera postupkom injekcionog brizganja, najvažnije je postići visoko automatizovanu proizvodnju, kod koje se ne treba naknadno obavljati nikakva dorada (samo u retkim slučajevima odvajanje ulivnog kanala).

Osnovni zadaci alata su: prihvatanje rastopa iz mlaznice jedinice za ubrizgavanje i njegovo hlađenje do postizanja forme otpreska, potiskivanje otpreska iz kalupne šupljine i ciklusni rad sistema injekcionog presovanja. Sve te postavljene zadatke alat ne može da izvrši ako nema sledeće elemente [4]:

- Ulivni sistem,

- Kalupnu šupljinu,

- Sistem za izbacivanje otpreska,

- Sistem za vođenje kalupa,

- Kućište i

- Elemente za temperiranje kalupa

$\mathrm{Na}$ slici 2 dat je šematski prikaz alata sa osnovnim komponentama: 1. Prsten za centriranje mlaznice, 2. Nepokretna stezna ploča, 3. Ulivna čaura, 4. Nepokretni kalup, 5. Segmentni umetak nepokretne strane, 6. Segmentni umetak pokretne strane, 7. Pokretni kalup, 8. Izbacivači, 9. Jezgra, 10. Međuploča, 11./12. Izbacivačke ploče, 13. Odstojnici ili distantne letve, 14. Pomična ili pokretna stezna ploča, 15. Protivpritisna čivija, 16./17. vođice i vodeće čaure, 18. Centrirani prsten, 19. Potiskivač, 20. Povratna opruga, 21. Spojni vijci, 22. Proizvod (otpresak), 23. Kanali za hlađenje (temperiranje).

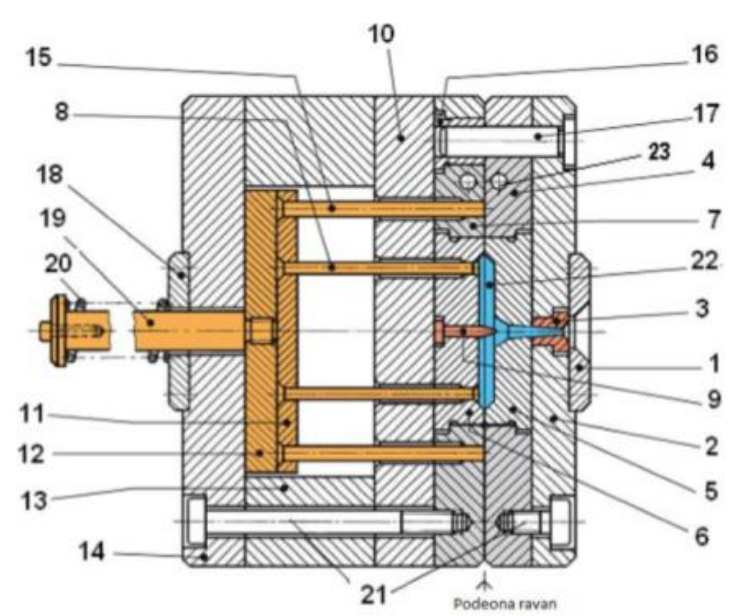

Slike 2. Struktura alata za injekciono presovanje [5]

\section{PROJEKTOVANJE ALATA ZA INJEKCIONO PRESOVANJE PROIZVODA OD PLASTIKE}

\subsection{Opis proizvoda od plastike}

Osnovni predmet istraživanja u ovom rada se odnosi na projektovanje i izradu alata za injekciono presovanje držača cevi za podno grejanje (slika 3). Osnovna namena proizvoda je pričvršćivanje i fiksiranje cevi na željeni razmak i distanciranje armaturne mreže od podloge.

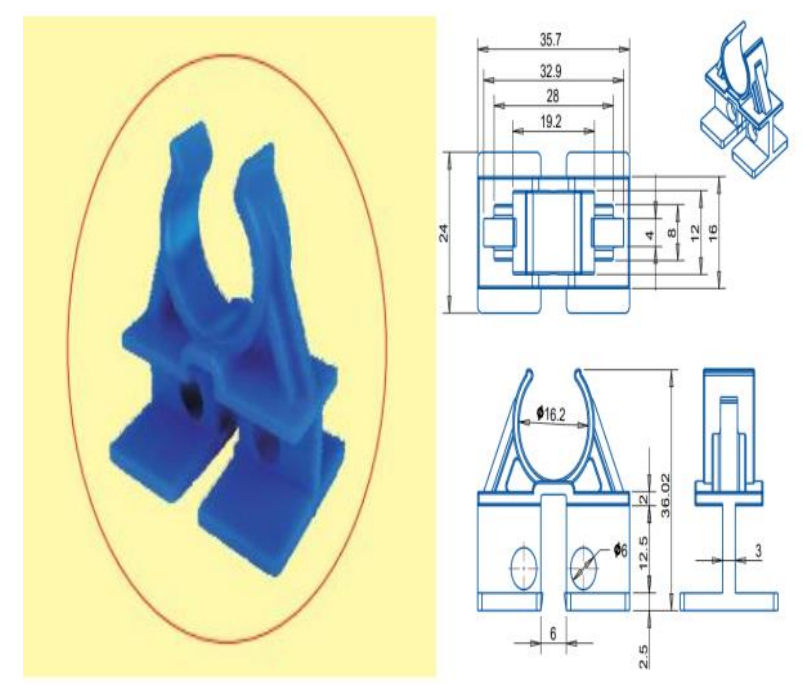

Slika 3. Držač cevi za podno grejanje [6]

\subsection{Analiza tehnologičnosti za proces injekcionog presovanja proizvoda}

Analiza tehnologičnosti konstrukcije dela je izvršena u okviru modula Mold Analysis programskog sistema PTC Creo Parametric. U okviru ovog modula mogu se dobiti svi neophodni podaci vezani za sam proces brizganja. Ti neophodni podaci se odnose na materijal koji se brizga, tok materijala pri brizganju, vreme punjenja pri brizganju, pritisak brizganja, pad pritiska brizganja, predviđen kvalitet, itd. Modul Mold Analysis omogućava analizu:

- Vremena punjenja kalupne šupljine,

- Pritiska,

- Temperature,

- Pouzdanost popunjavanja kalupa,

- Vremena hlađenja, itd. 
Na slici 4 prikazani su izlazni rezultati simulacije vremena punjenja kalupa plastičnom masom.

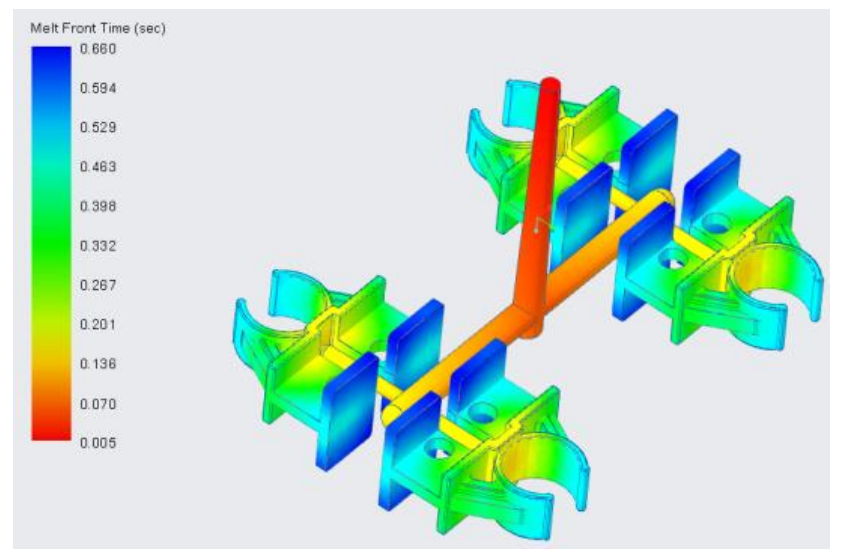

Slika 4. Simulacija vremena punjenja kalupa

Nakon softverske analize usvojeni su sledeći podaci procesa brizganja posmatranog proizvoda, prema tabeli 1 .

Tabela 1. Parametri brizganja proizvoda

\begin{tabular}{|l|c|}
\hline Vreme punjenja & $0.69 \mathrm{~s}$ \\
\hline Temperatura topljenja & $250^{\circ} \mathrm{C}$ \\
\hline Maksimalni injekcioni pritisak & $155 \mathrm{Mpa}$ \\
\hline
\end{tabular}

\subsection{Definisanje nepokretne strane alata}

Sklop nepokretne strane alata prikazan je na slici 5.

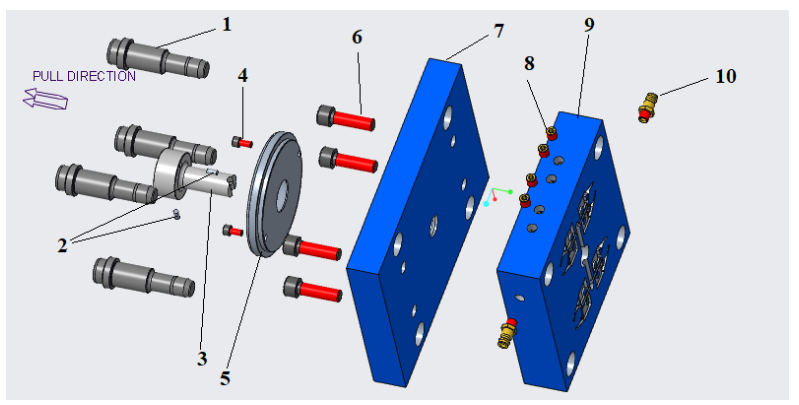

Slika 5. Nepokretna strana alata

Elementi sa slike 5 su: 1 - Vođice koja služi za vođenje nepokretne strane alata. 2 - Čivije (Ø4 x 8 mm), služe za fiksiranje dizne kako ne bi došlo do njenog obrtanja oko sopstvene ose. 3 - Dizna koja sprovodi rastopljeni polimer do kalupne šupljine. 4 - Vijak M5, služi za povezivanje centrirnog prstena (5) i osnovne ploče (7). 5 - Centrirni prsten na koji se dovodi mlaznica mašine. 6 Vijak M10 povezuje osnovnu (7) i kalupnu ploču (9). 7 Osnovna nepokretna ploča. 8 - Element sistema za hlađenje - čep. 9 - Nepokretna kokila. 10 - Element sistema za hlađenje - priključak.

Kalupna ploča je od niskolegiranog čelika Č.4742 dok je osnovna ploča od ugljeničnog čelika Č.1730.

\subsection{Definisanje pokretne strane alata}

Sklop pokretne strane alata prikazan je na slici 6 . Elementi sa slike 6 su: 1 - Vijak M10 koji služi za povezivanje osnovne ploče (1), distantne letve (5), međuploče (10) i pokretne kokile (11). 2 - Osnovna pokretna ploča. 3 - Čaura, služi za centriranje pokretnog dela alata. 4 - Vijak M8 povezuje ploče izbacivačkog sklopa. 5 - Distantna letva, zajedno sa izbacivačkim pločama obezbeđuje dužinu hoda izbacivača koji je ovde $30 \mathrm{~mm}$. 6 - Ploča oslonca izbacivača, na nju se oslanjaju izbacivači. 7 - Noseća ploča izbacivača, ploča u koju se postavljaju i koja nosi izbacivače. 8 - Čaura, služi za centriranje i vođenje pokretne strane alata. 9 - Izbacivači i povratnici. Povratnici izbacivača, $u$ kontaktu sa nepokretnom stranom alata vraćaju izbacivački sklop u prvobitni položaj. 10 - Međuploča. 11 - Pokretna kokila. 12 - Element sistema za hlađenje - priključak. 13 Element sistema za hlađenje - čep.

Pokretna osnovna ploča (2), distantne letve (5), izbacivačke ploče $(6,7)$ i međuploča (10) su od ugljeničnog čelika Č.1730 dok je pokretna kokila (11) od niskolegiranog čelika Č.4742.

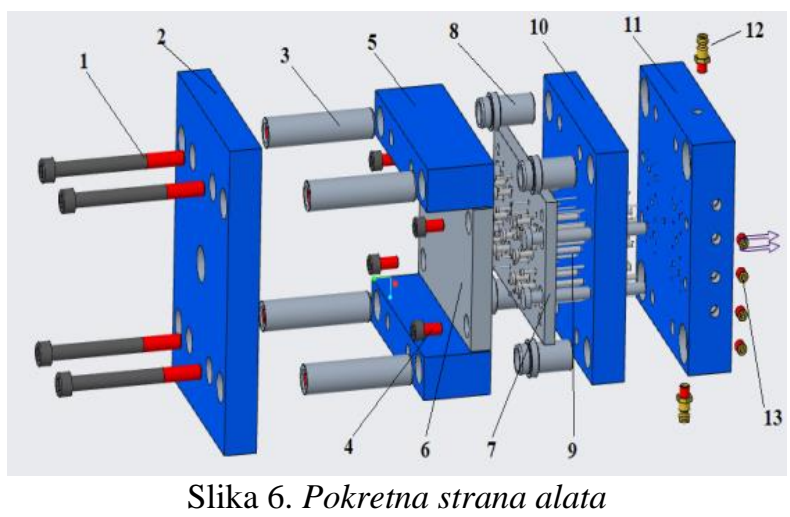

\section{PROJEKTOVANJE TEHNOLOŠKOG PROCESA IZRADE KALUPNIH PLOČA}

Mnoge kompanije, među kojima je i Meusburger se bave proizvodnjom $\mathrm{i}$ prodajom elemenata $\mathrm{za}$ alate $\mathrm{za}$ injekciono presovanje plastike, čime se omogućava kupovina već obrađenih ploča sa standardnim otvorima za vođice (čaure) i rupama za vijke koji služe za spajanje sa ostalim delovima alata. Tako da proizvođaču alata ostaje samo obrada gravure, otvora za izbacivače, ulivnih kanala i otvora za hlađenje što znatno ubrzava proces proizvodnje.

U okviru [6] projektovani su tehnološki procesi izrade pokretne i nepokretne kokile u vidu sadržaja tehnološkog procesa (slika 7) i preciziranih karti operacije izrade gravure kokila, na bazi čega su primenom CAM sistema generisne upravljačke informacije za CNC obadu.

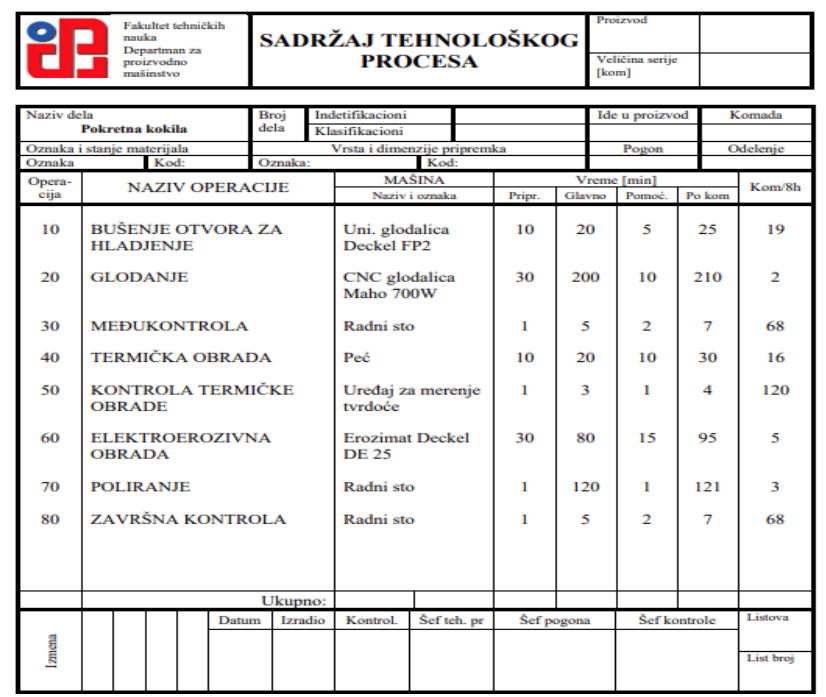

Slika 7. Sadržaj tehnološkog procesa izrade kokile 


\subsection{Izrada gravure primenom CAM modula programskog sistema Creo Parametric}

CAM (Computer-Aided Manufacturing) je računarom podržana proizvodnja i obuhvata sve faze proizvodnje u smislu optimizacije korišćenja velikog broja podataka. Osnovna ideja ovakvog načina razvoja tehnologije je da se kompjuter koristi u svrhu generisanja upravljačkih programa za CNC (Computer Numerical Control) mašine alatke. Potreba za razvojem ovakvih programskih sistema proistekla je iz potrebe da se na CNC mašinama alatkama izrađuju delovi složene geometrije brzo, kvalitetno i efikasno. Na slici 8 je prikazan izvod iz simulacije zahvata obrade finog glodanja gravure nepokretne kalupne ploče.

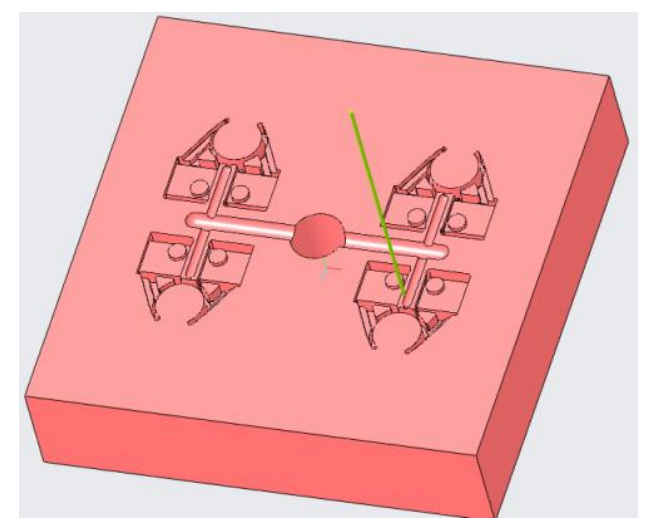

Slika 8. Simulacija zahvata obrade kalupne ploče

\subsection{Obrada gravure EDM obradom}

Određene površine gravure nije moguće potpuno obraditi glodanjem, zbog toga je potrebno konstruisati pune elektrode za obradu na erozimatu. U zavisnosti od vrste i kvaliteta obrade, erodiranje se izvodi sa jednom ili više elektroda. Najčešće se obrada izvodi sa dve (gruba+fina) ili tri (gruba+prethodna+fina) elektrode. Elektrodom za grubu obradu odnosi se skoro celokupni deo materijala, a za finu obradu ostavlja se samo onoliko materijala koliko je potrebno da se uklone neravnine i oštećenja u površinskom sloju koji su nastali pri gruboj obradi. Korišćene elektrode treba prethodno obraditi na $\mathrm{CNC}$ glodalici i njihovi 3D modeli su prikazani na slici 9.

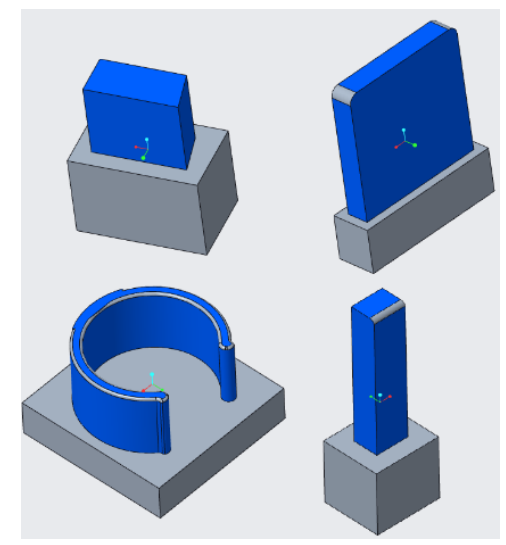

Slika 9. Elektrode za EDM obradu

\section{ZAKLJUČAK}

Kao rezultat opšte prisutnih težnji prilagođavanja savremenim zahtevima tržišta, postavljaju se novi i sve slože- niji zahtevi pred proizvodne sisteme, što se u velikoj meri ogleda u potrebi za visokim stepenom automatizacije svih aktivnosti, počevši od razvoja i projektovanja proizvoda pa sve do njihove proizvodnje. U poslednje vreme javlja se sve veća potražnja za proizvodima od plastike, a samim tim i za alatima za njihovu proizvodnju, koji u velikoj meri utiču na kvalitet, vreme i troškove njihove proizvodnje. Cilj ovog rada bio je opis projektnih aktivnosti tehnološke pripreme proizvodnje proizvoda od plastike: definisanje konkretnog proizvoda, u ovom slučaju držača cevi za podno grejanje, projektovanje alata za zadati proizvod i projektovanje tehnološkog procesa izrade njegovih vitalnih delova - kokila.

Alati za injekciono presovanje predstavljaju složeni sistem, sastavljen od velikog broja elemenata, što pre svega zavisi od oblika i broja predmeta koji se u njemu dobijaju. Projektovanje alata pomoću savremenih programskih paketa u velikoj meri olakšava rad projektantima.

Zahvaljujući standardizovanju elemenata alata smanjeno je vreme izrade celokupnog alata i njegove cene koštanja. Mnogobrojna istraživanja su pokazala da se $55 \%$ vremena troši za izradu delova kalupne šupljine, a $45 \%$ za izradu kućišta. Upotrebom standardnih delova postignuti su kratki rokovi izrade kalupa, visok kvalitet, kao i manji troškovi. Upotrebom CAM softvera u velikoj meri se skraćuje generisanje upravljačkih programa za obradu na CNC mašinama, a samim tim se povećava proizvodnost i ekonomičnost poslovanja.

\section{LITERATURA}

[1] Perošević, B.: Kalupi za injekciono presovanje plastomera (termoplasta), Naučna knjiga, Beograd, 1995.

[2] Vilotić, D.: Tehnologija injekcionog presovanja polimera, skripta sa predavanja, FTN, Novi Sad, 2015.

[3] Lukić, D., Milošević, M., Todić, V.: Integrisani CAPP sistemi i tehnološka baza podataka, skripta sa predavanja, FTN, Novi Sad, 2014.

[4] Lukić, D.: Razvoj sistema za automatizovano projektovanje tehnoloških procesa izrade alata za brizganje plastike, magistarska teza, FTN, Novi Sad 2007. [5] Milutinović, M.: Alati za injekciono presovanje, skripta sa predavanja, FTN, Novi Sad, 2017.

[6] Kiš, S.: Tehnološka priprema proizvodnje alata za injekciono presovanje držača cevi za podno grejanje, Master rad, FTN, Novi Sad, 2020.

\section{Kratka biografija:}

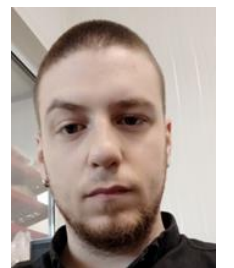

Stevan Kiš rođen je u Rumi 1996. god. Master rad na Fakultetu tehničkih nauka iz oblasti Mašinstva - Proizvodno mašinstvo, smer Računarom podržane tehnologije obranio je 2020. god.

kontakt: stevan.kis1@gmail.com

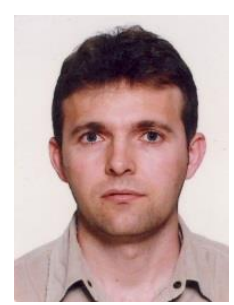

Dejan Lukić rođen je u Žablju 1973. god. Doktorirao je na Fakultetu tehničkih nauka 2012. god., a od 2018 je u zvanju vanrednog profesora. Oblast interesovanja je projektovanje tehnoloških procesa, CAD/CAPP/CAM, DfM, optimizacija i logistika proizvodnje, Industrija 4.0. 